\title{
Analysis of Mechanical Properties of Aluminium Weldments as Supporting Material in Shipping Industry
}

\author{
J Purnomo $^{1}$, Suhartiny ${ }^{2}$, S Djulis ${ }^{3}$, N Almuzani ${ }^{4}$ \\ \{ipurnomoj@yahoo.com ${ }^{1}$,sunysuhartiny@yahoo.com²,limas_sukma@yahoo.com³ \\ nafistip@yahoo.co.id $\left.{ }^{4}\right\}$ \\ ${ }^{1,2,3,4}$ STIP (Sekolah Tinggi Ilmu Pelayaran) Jakarta, Indonesia
}

\begin{abstract}
One of the main problems faced in the process of aluminum welding is a selection of the appropriate combination of inputs to achieve the required quality. In this paperwork, different size of filler wire and current settings will be used to clarify the mechanical properties of the aluminum weldment. Total of specimens to be carried out are 40 types. Butt joint is selected as a joining for this experiment. It will divide into two types, V-groove, and Straight groove. Tungsten Inert Gas (TIG) is used as a welding process in this experiment. All of the specimens will be tested using strength test. The result of the test was evaluated and compared to determine the appropriate settings for aluminum weldment. The result shows that the best parameter for $\mathrm{V}-$ groove joining is 3 $\mathrm{mm}$ with 100 amperes of current setting. For the $\mathrm{S}-$ groove, the best parameter joining is $1 \mathrm{~mm}$ of filler wire with 100 amperes of current setting where it gave a strong joint between two plat of aluminum.
\end{abstract}

Keywords: properties, weldments, V-groove, S-groove, strength test.

\section{Introduction}

The action of inter-atomic or intermolecular forces as opposed to purely macroscopic or even microscopic mechanical interlocking forces. Meanwhile, aluminum is a silvery-white and ductile member of the boron group of chemical elements. It has the symbol Al. Its atomic number is 13. It is not soluble in water under normal circumstances. Aluminum is the most abundant metal in the Earth's crust, and the third most abundant element therein, after oxygen and silicon. It makes up about $8 \%$ by weight of the Earth's solid surface. Aluminum is too reactive chemically to occur in nature as free metal. Instead, it is found combined in over 270 different minerals. The chief source of aluminum is bauxite ore[1].

Miler [2]The characteristic of aluminum have an impact on this project. The selection of the process must be chosen wisely. The problems that will occur in this project are the suitable current setting that will be used for aluminum. (80A, 100A) and the suitable filler wire diameter. (1mm, 3mm)[3].

[7]The objectives of the research are: i)To evaluate the mechanical properties by applying tensile test. ii)To study the suitable diameter of filler wire that can be applied for aluminum weldment. iii)To study the suitable impact of current that can be applied to aluminum weldment. [8] The research will be conducted within the following limits: i)Welding equipment: TIG welding. ii)Type of joint: Butt joint (straight and V-groove). iii) Base metal: Aluminum (Al) . 


\section{Result and Discussion}

Experimental activity was conducted to obtain data in order to determine the mechanical properties of an aluminum weldment. The first step is preparing the plate specimen. The specimen is cut into $50 \mathrm{~mm} \times 20 \mathrm{~mm}$. The welding activity will take place using TIG welding equipment. Testing specimen by applying strength test is the last step for this experiment. The parameters for the analysis will be discussed later. After deciding on the material (ANSI 6064) and select the appropriate parameter, the specimen will be cut into the desired size $(50 \mathrm{~mm} \mathrm{x}$ $20 \mathrm{~mm}$ ). The cutting procedure will be conducted using Shearing Machine. Due to the accuracy in cutting, the machine will perform the cutting for all specimens (40 pieces of plate).Some of the specimen will undergo a 30 degree of $\mathrm{V}$ groove shape. The risk of the melt can be reduced and automatically can save cost. This will make the penetration of the weld metal be maximized and contributed to the strength of the weldment itself

\subsection{Comparison of Yield Load}

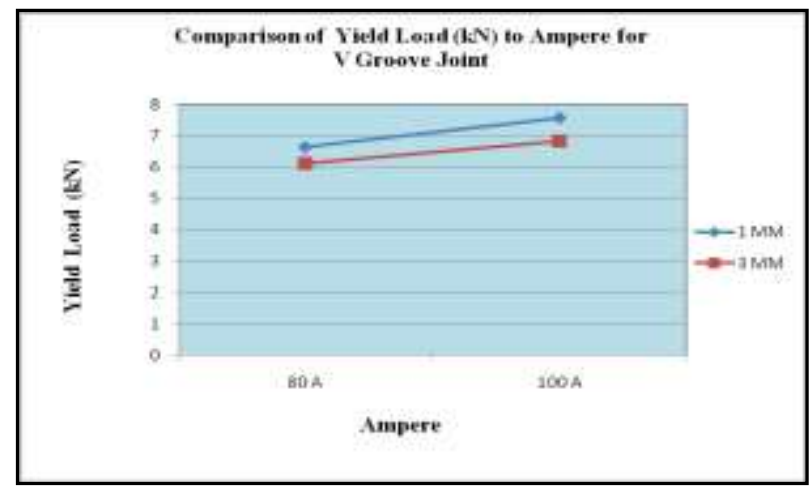

2.2 Comparison of Modulus

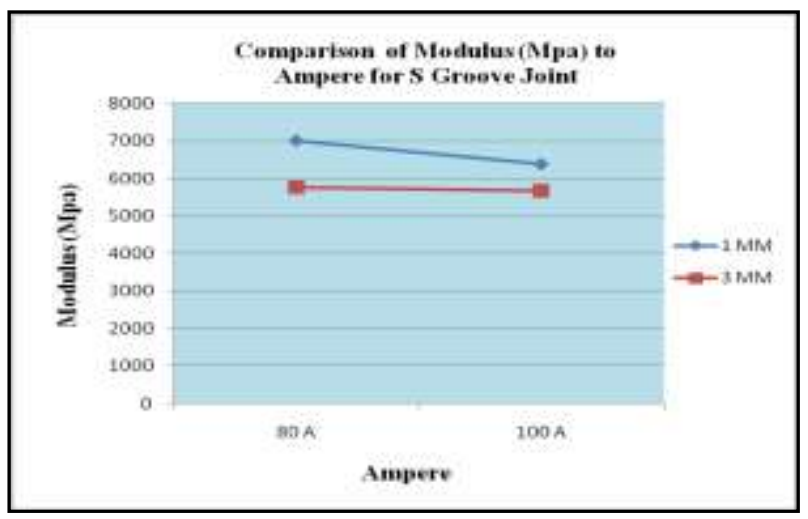


2.3 Comparison of Load at Brea
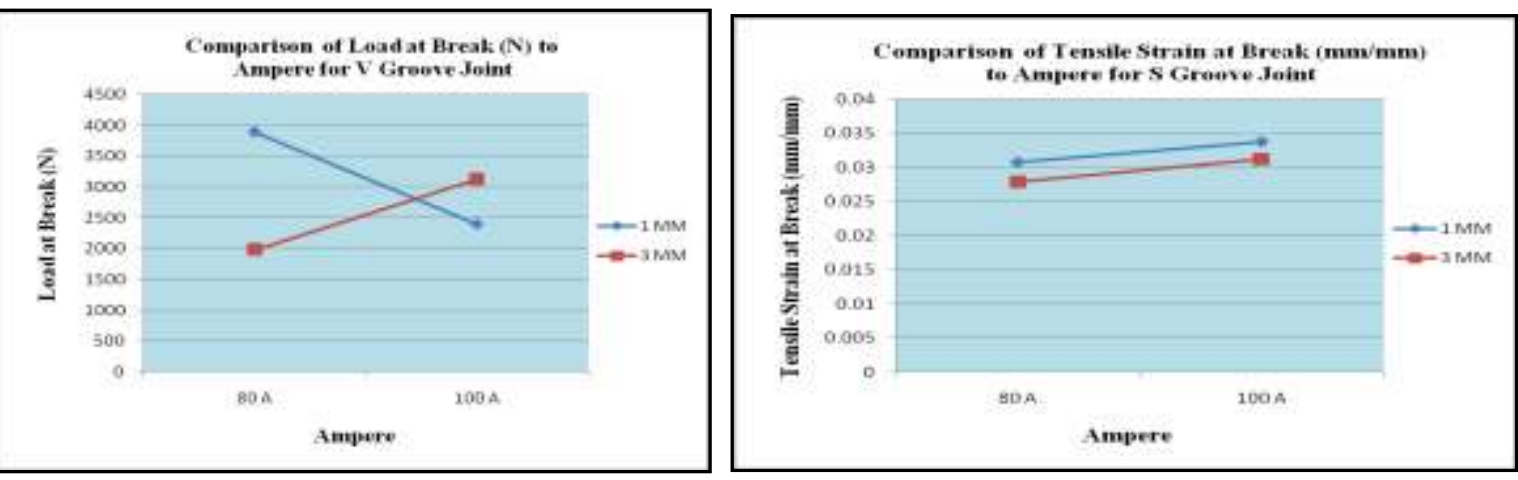

2.4 Comparison of Tensile Strain at Break
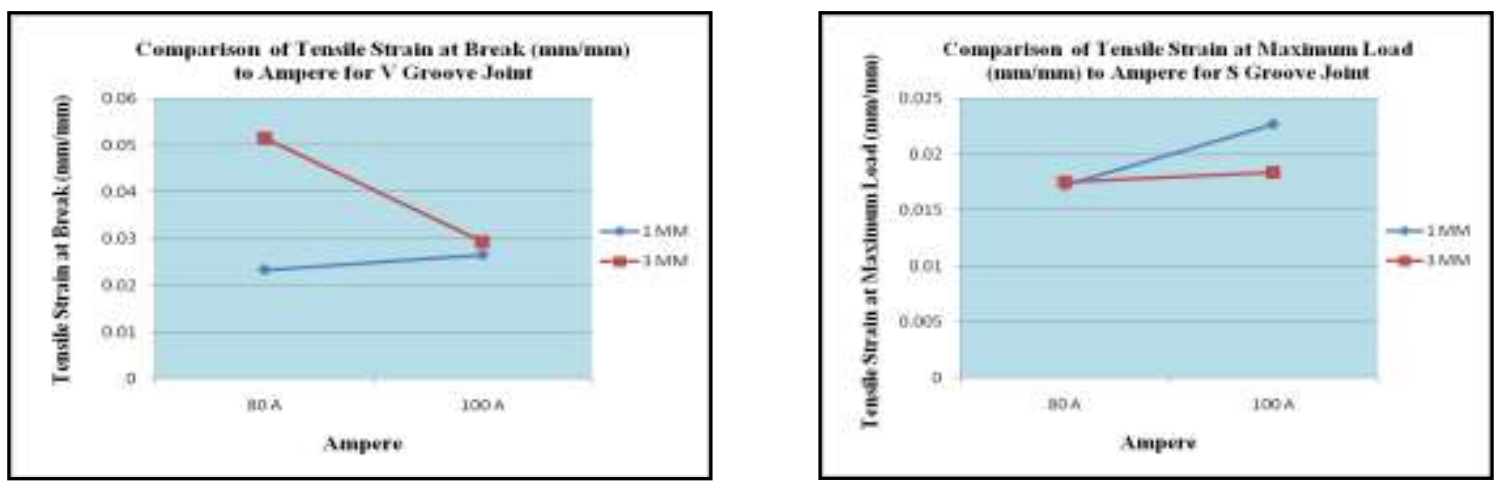

2.5 Comparison of Tensile Strain at Maximum Load

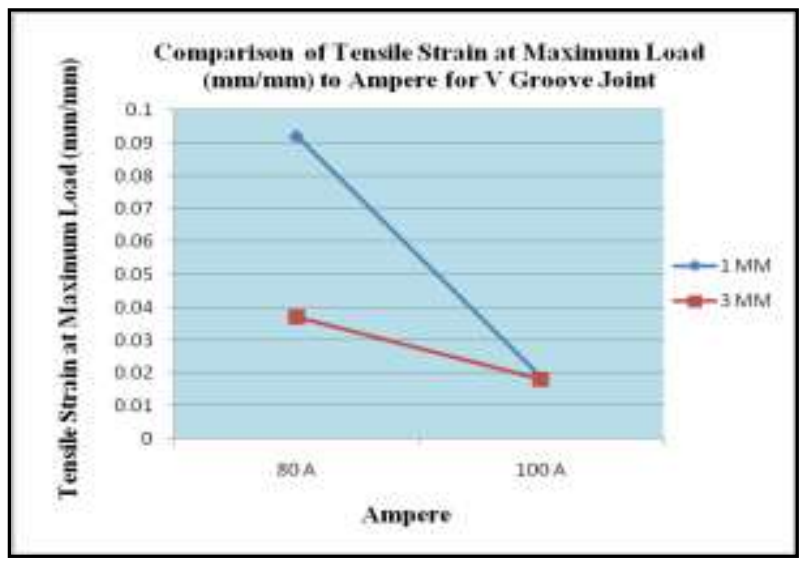


From the entire graph, the parameter $3 \mathrm{~mm}$ of filler wire with 100 amperes is suitable for $\mathrm{V}$ groove joining because of the gap from $\mathrm{V}$ groove can be refilled with the bigger diameter of filler wire. $\mathrm{V}$ groove joining is not suitable for the aluminum with the thickness of $5 \mathrm{~mm}$ because aluminum easy to melt so the penetration is not stable while doing the welding process. For the best result, square groove is more preferable with the parameter of $1 \mathrm{~mm}$ of filler wire diameter with the 100-ampere current setting.Discussion

Based on the results of testing the influence of salinity and the degree of acidity $(\mathrm{pH})$ against corrosion rate on steel plate material existing ships in 3 (three) the location of the port of Tanjung Priok Harbor, Muara Angke and the port of Sunda Kelapa, then gave an overview the influence of salinity and the degree of acidity of the greatest happening is in the port of MuaraAngke, followed by the port of Sunda Kelapa and lowest in Tanjung Priok. The effect of $\mathrm{pH}$ (degree of Acidity) this is the number of ions $\mathrm{H}+$ or $\mathrm{Oh}-$ around the waters of the harbor that is worth 0.7 so affect $<$ rate of corrosion on the steel plate material surrounding the port ships.

According to Mackereth[4], $\mathrm{pH}$ conditions closely related to carbon dioxide (CO2) and alkalinity. Alkalinity, in General, show a concentration of alkaline or materials that can neutralize the acidity in water. The higher the $\mathrm{pH}$, the higher the value of alkalinity and the lower levels of carbon dioxide (CO2) that is free. Other than alkalinity concentrations, DIC (dissolved inorganic carbon) and temperature is also an important factor in regulating the $\mathrm{pH}$ of seawater. The value of the DIC high will result in an increase of the hydrogen ions so that the $\mathrm{pH}$ of seawater (acid). The temperature will also indirectly affect the magnitude of the $\mathrm{pH}$ value, i.e. the value of big DIC when low temperatures, so a low temperature will result in the $\mathrm{pH}$ of seawater that is low in pula (Suciaty, 2011). The purpose of this study was to calculate the variation of the $\mathrm{pH}$ of the ocean waters of Indonesia in the past 18 years, knows the influence the condition of seasonal, annual and dynamics between the waters of according to Mackereth[4], $\mathrm{pH}$ conditions closely related to carbon dioxide

(CO2) and alkalinity. Alkalinity, in General, show a concentration of alkaline or materials that can neutralize the acidity in water. The higher the $\mathrm{pH}$, the higher the value of alkalinity and the lower levels of carbon dioxide (CO2) that is free. Other than alkalinity concentrations, DIC (dissolved inorganic carbon) and temperature is also an important factor in regulating the $\mathrm{pH}$ of sea water. The value of the DIC high will result in an increase of the hydrogen ions so that the $\mathrm{pH}$ of seawater (acid). The temperature will also indirectly affect the magnitude of the $\mathrm{pH}$ value, i.e. the value of big DIC when low temperatures, so a low temperature will result in the $\mathrm{pH}$ of sea water that is low in pula (Suciaty, 2011). The purpose of this study was to calculate the variation of the $\mathrm{pH}$ of the ocean waters of Indonesia in the past 18 years, knows the influence the condition of seasonal, annual and dynamics between the waters of the According to Mackereth et al., (1989), $\mathrm{pH}$ conditions closely related to carbon dioxide (CO2) and alkalinity. Alkalinity, in General, shows a concentration of alkaline or materials that can neutralize the acidity in water. The higher the $\mathrm{pH}$, the higher the value of alkalinity and the lower levels of carbon dioxide (CO2) that is free. Other than alkalinity concentrations, DIC (dissolved inorganic carbon) and temperature is also an important factor in regulating the $\mathrm{pH}$ of sea water. The value of the DIC high will result in an increase of the hydrogen ions so that the $\mathrm{pH}$ of seawater (acid). The temperature will also indirectly affect the magnitude of the $\mathrm{pH}$ value, i.e. the value of big DIC when low temperatures, so a low temperature will result in the $\mathrm{pH}$ of seawater that is low in pula.The purpose of this study was to calculate the variation of the $\mathrm{pH}$ of the ocean waters of Indonesia in the past 18 years, knows the influence the condition of seasonal, annual and dynamics between the waters of according to Mackereth[4], $\mathrm{pH}$ conditions closely related to carbon dioxide 
(CO2) and alkalinity. Alkalinity, in General, show a concentration of alkaline or materials that can neutralize the acidity in water. The higher the $\mathrm{pH}$, the higher the value of alkalinity and the lower levels of carbon dioxide $(\mathrm{CO} 2)$ that is free. Other than alkalinity concentrations, DIC (dissolved inorganic carbon) and temperature is also an important factor in regulating the $\mathrm{pH}$ of seawater. The value of the DIC high will result in an increase of the hydrogen ions so that the $\mathrm{pH}$ of seawater (acid). The temperature will also indirectly affect the magnitude of the $\mathrm{pH}$ value, i.e. the value of big DIC when low temperatures, so a low temperature will result in the $\mathrm{pH}$ of seawater that is low in also.

The purpose of this study was to calculate the $\mathrm{pH}$ variation of Indonesian waters in the

past 18 years, to determine the effect of seasonal, inter-annual conditions and waters dynamics on the $\mathrm{pH}$ of Indonesian marine waters, and to see the relationship between chemical parameters and marine physics to marine $\mathrm{pH}$ concentrations.

In general sea and coastal waters have a relatively more stable $\mathrm{pH}$ and are in a narrow range, usually ranging from 7.6 to 8.3 which means alkaline or called alkali [5]But in certain conditions, the value can change to be lower so that it becomes acidic. Such changes in $\mathrm{pH}$ values can affect the quality of the waters which in turn will have an impact on the life of the biota in it. The amount of waste originating from households, chemical industries, and fossil fuels into waters can affect the $\mathrm{pH}$ value in it. According to the quality standard KMN-KLH PP No.1 of 2010 concerning the management of water pollutants, the $\mathrm{pH}$ parameter values are included in the normal category, ranging from 6-9.

\section{Conclusion}

This experiment has been done to study the mechanical properties of an aluminum weldment. The experiment is done using TIG welding and used aluminum as a filler wire with variable diameter of filler wire and current setting. The totals of specimen are 40 pieces and were tested using tensile test. The analysis of mechanical properties has been done in this experiment. From the resulting experiment, the relationship between parameters and mechanical properties of aluminum weldment is determined. Through the mechanical properties analysis, the diameter of filler wire gives the main effect in this study. The increasing of the diameter will make the weldment joint stronger especially for $\mathrm{v}$-groove joining. It is because of space is huge and the biggest diameter of filler wire is needed. Actually, v-groove joining is not suitable for this experiment because of the thickness of the plate is low. The best parameter for $\mathrm{V}$ - groove was $3 \mathrm{~mm}$ of filler wire with 100 amperes while for $\mathrm{S}$ - groove, the best parameter was $1 \mathrm{~mm}$ of filler wire with 100 amperes of current setting.

\section{References}

[1] J. Purnomo, “AN ANALYSIS OF MECHANICAL PROPERTIES OF ALUMINIUM WELDMENTS,” in PROSIDING SEMNASTEK 2019, 2019.

[2] Miler, "Guidelines For Gas Tungsten Arc Welding."

[3] P. M. Mumford, “'Tensile Testing.' Test Methodology and Data Analysis,” P. Han Ed ASM Int., pp. 49-60, 1992.

[4] F. J. H. Mackereth, J. Heron, and J. . Talling, Water Analysis. United Kingdom: Cumbria UK, 1989.

[5] G. Chryssolouris, D. Mavrikios, and D. Mourtzis, "Manufacturing Systems Skills \& Competencies for the Future," in Procedia CIRP, Keynote paper of the 46th CIRP 
Conference on Manufacturing Systems 2013, 2013, vol. 7, pp. 17-24. 
